\title{
Kahoot with Smartphones in Testing and Assessment of Language Teaching and Learning, the Need of Training on Mobile Devices for Vietnamese Teachers and Students
}

\author{
Thuy Thi Thanh Nguyen and Takashi Yukawa
}

\begin{abstract}
The underlying purpose of this research was examining the use of Kahoot in practice to test and revise what students had been learning at class to determine its viability as a supplement to existing materials. Twenty teachers and twenty students of English major were asked about Kahoot and its uses in teaching and learning. Pre-survey questionnaires showed that none teachers or students had used Kahoot in testing or assessment, only one teacher had heard of Kahoot before but had not actually used it. Regarding the students' habit of technology in learning, all twenty students were engaged with using their smartphones to revise content covered in class. All students agreed to take part in a three-week pilot study using Kahoot as a supporting tool. This involved training teachers in using Kahoot, requiring teachers to design quizzes and brief tasks to test and assess the students' outcomes after classes. The students created a Kahoot account for an analysis of student usage. Technical and networking problems did hinder usage of Kahoot, but both teachers and learners indicated it was still beneficial. The results of using Kahoot in testing and assessment are discussed in terms of the implications for teachers, students, and the curriculum.
\end{abstract}

Index Terms-Kahoot introduction and application, mobile device, online testing and assessment, teachers' and learners' attitudes towards Kahoot.

\section{INTRODUCTION}

Learning is influenced by social interactions, interpersonal relations, and communication with others, and learners need opportunities for positive interactive and collaborative tasks [1], [2]. More recent research suggests that collaboration online promotes sustained task orientation and advanced knowledge construction [3].

Mobile devices are an ever increasing in modern society and therefore, are finding their way into every aspect of our lives.

The use of digital technology for educational purposes, including second and foreign language learning, is rapidly expanding. Most students would expect to use digital devices to carry out an Internet search when they write a paper to look for an appropriate website to practice a language skill. More individuals tend to have more than one mobile device and use them on a daily basis [4]. In an educational context, mobile devices offer new possibilities to support teaching and learning [5]. However, it is not clear whether digital

Manuscript received October 12, 2018; revised January 23, 2019.

The authors are with Knowledge System Laboratory, Information Science and Control Engineering Department, Nagaoka University of Technology, Nagaoka, Niigata, Japan (e-mail: thuy@nut-kslab.net, yukawa@vos.nagaokaut.ac.jp). technology is used to the same degree in assessing outcomes as it is in creating learning opportunities for students.

Twyman [6] pointed out that there have been historical barriers to assessment including difficulties in "simultaneously teaching and measuring" (p.104); that is, it can be very challenging for teachers to carry out the twin roles of teaching and assessing. It is crucial; therefore, to see if there are affordances of technology for assessment that can be taken advantage of.

"Technology fluency" is one of the challenges facing language teachers in linking technology and assessment in order to use digital tools for assessment in general [7] (p.11).

The procedures of testing and assessment after every lesson are based on both traditional and interactive methods which require teachers to boost their students' interests and concentration on reviewing, revising and reinforcing their book-based knowledge. In terms of testing and assessment, among several online formative assessment tools such as Socratives, or Geddit, Kahoot was considered a connective approach for teachers to test students' learning acquisition after every lesson. Kahoot, chosen as an online assistance for testing and assessing learners, significantly shed a light on the possibility of differentiating assessment tools in teaching.

In terms of second / foreign language acquisition, smartphones are powerful tools for assisting language learning as they provide learners with mobile and independent access to language learning materials and resources [8]. Smartphones also assist language learning by offering rich graphics, high quality audio and video, and a high degree of interactivity [9].

It is evident that the adoption of mobile devices for learning has enormous influence on education. For example, the results of the Pearson student mobile device survey reported by Poll [10] showed that $84 \%$ of US college students own a smartphone, $83 \%$ of them regularly use a smartphone, and that $56 \%$ of them use a smartphone every week in order to do their school work. The figures clearly show that modern students look at the smartphone as the preferred interface for communication and for study [11].

Since more than half of the college student population are social networking app users, Tapshield [12], and researchers [13], [14] have noted the potential of social networking apps in education, it is important to research the use of such apps in teaching and learning a second language. Most of the current smartphone studies have a focus on the pedagogical aspects (e.g., teaching of grammar, culture, or vocabulary). Studies on the use of online application from social media for language teaching procedures, particularly in language 
testing and assessment, are scare.

Hence, the purpose of this study is to investigate into the potential use of Kahoot as an online gaming web-based site in English-as-a-foreign-language teaching procedures to test and assess language students' learning and outcomes after classes. Questions are redesigned in the formats of quick quizzes or short tests by teachers using Kahoot application as a fun interactive learning game. The speed of memorizing, understanding and the learning outcomes of learners will also be reflected.

The study attempts to introduce Kahoot, which is considered new to the Vietnamese college teachers and students as an online exported testing and assessment tool. Furthermore, teachers and learners' attitudes towards the use of Kahoot will be described in this study; therefore, practical recommendations in terms of testing and assessment tools will be provided. This research calls for a training in using Kahoot as an online assessment tool to language teachers and learners via mobile devices such as smartphones.

\section{LITERATURE REVIEW}

Technology-enabled social interactions and the integration of mobile applications into teaching have been put into a variety of relevant studies in the current realm of digital society. The pervasive character of social networks has also had a critical impact on the perceptions of learning. The essence of technology, social networks and social media in education, related literature of mobile learning, and the need of social networking devices' training will be presented in this review section.

\section{A. The Use of Technology in Language Testing and Assessment}

Various recent trends in technology and assessment of language learning are being examined in this part of the paper. First, what assessment is defined and then how technology can be used for assessing learning. In particular, the paper will highlight ways in which the affordances of digital technology are widening the opportunities for teachers to assess learning in different ways. These include the use of technology to enhance testing and assessment learners' outcomes, and to provide alternative assessments of language knowledge and skill development.

For the purposes of this paper, assessment is defined as the process of gathering evidence of student learning. Teachers use tests, presentations, observations, and class work to assess student learning [15]. Basically, there are two kinds of assessment, which are formative and summative. The former is to guide and support future learning and the latter is to assess what has been learnt during a course of study. However, in practice, it is often very difficult to distinguish clearly between the two as both types can give useful information for students' learning [15].

In terms of benefits of online testing [16] (pp. 43-45), digital technology has been used in basic assessment methods through automated marking of computer tests and quizzes. As well as speeding up the process of marking, this can give teachers valuable information about what students have or have not learned which they can use for grading and to plan future lessons. Together with providing teachers with assessment opportunities, many software tools are particularly suited for student self-assessment. Examples can be automatic speed recognition for pronunciation modeling (e.g., www.englishcentral.com); automated marking and feedback on writing that give guidance on structure grammar and vocabulary use (e.g., www.ets.org/criterion); and, grammar and vocabulary applications that assess a learners' level and provide regular review through spaced repetition flashcards and language games (e.g. www.wordengine.jp). Such tools have the potential to enhance student independence and learner autonomy by providing regular automated assessment and feedback.

Web 2.0 tools and websites can be used for the assessment of other skills and competencies [17]. They stated that assessment has had a traditional focus on language mechanics such as written tests on vocabulary and structure; however, there is an increasing focus on communicative competence, which is supposed to be far more useful for learners with the support of technology.

By using Web 2.0 tools teachers have access to the products and processes of learning that were not previously possible and in doing so technology can support assessment that is "constructive aligned" [18] with teaching and learning; that is, technology can help in the assessment of real world tasks and learning outcomes.

For example, Tricider tool (http://tricider.come/en/t) which allows teachers to track the contribution of individual students to a collaborative brainstorming process, even if the students or teachers are not present in the classroom was suggested [17]. It can be seen that digital technology such as Web 2.0 tools can be used to provide evidence for both traditional language learning targets such as grammar and vocabulary items and newer digital products that are created and shared collaboratively.

Another trend with particular relevance is an increasing emphasis in many countries on measuring learning outcomes by using technology. This is the result of a number of factors such as governmental pressure for evidence of learning and technological advances in "learning analytics" [19]. Collected data includes the number of visits that students make to a learning site or application; the amount of time that is spent on each visit; the items of learning that cause most or least difficulty, and so on. Learning and Teaching Council Priority Project, 2009-2010 on the use of Web 2.0 tools in higher educational institutions [20] and the University of New South Wales website which has a large variety of assessment tools and staff development materials to support teachers in carrying out online learning [21].

Such learning analytic tools have the potential to be used to personalize learning and increase formative assessment which can lead to improved teaching and more empowered students [22].

It was emphasized how assessment and timely feedback by using technology can support better student learning [23], [24].

In sum, technology is being used for the assessment of language learning in many ways and can result in advantages over traditional alternatives. 


\section{B. Games in Language Teaching and Learning, Testing} and Assessment

Language games are not activities mainly aimed to break the ice between students or to kill time. Byrne [25] gave the definition to games as a form of playing governed by rules. They should be joyous and fun. Similarly, Hadfield [26] defined games as "an activity with rules, a goal and an element of fun." "Games are highly motivating because they are amusing and interesting. They can be used to give practice in all language skills and be used to practice many types of communication." [27]

The main reason why games are considered effective learning aids is that "they spur motivation and students get very absorbed in the competitive aspects of the games; moreover, they try harder at games than in other courses" [28].

Naturally when playing games, students are trying to win or to beat other teams for themselves or on behalf of their team. They are so competitive while playing because they want to have a turn to play, to score points and to win. As a result, in the class, students will definitely participate in the activities when teachers hold fun and interactive activities such as games. Therefore, it is possible for a teacher to introduce students to new ideas, grammar, and knowledge related to the learning objectives, then to test and assess the learning outcomes afterwards. Kahoot is designed to provide learners with collaboration in studying to promote learning motivation. When playing Kahoot, either individually or collaboratively, students enhanced their knowledge and skills in language acquisition. According to Richard-Amato [29], even though games are often associated with fun, we should not lose sight of their pedagogical values, particularly in second language teaching. Testing and assessment are also focused to assure the efficiency of teaching and learning processes. When book-based knowledge is delivered to learners, there should be appropriate tools to test and assess the learning acquisition. These procedures come along together for a balanced assessment and effectiveness in teaching and learning process. In the positive sense of games, Kahoot is recommended with its benefits and convenience as an alternative in testing and assessment materials. Kahoot saved teachers' time in creating various activities at class. Therefore, Kahoot can be considered an effective gaming assistance for teachers in teaching material diversity.

\section{Mobile Learning}

Integration of technology into teaching and learning with the assistance of mobile devices has been such a potential in the volume of research over the past several years. Digital technology in education has been attributed many affordances such as adding authenticity to the learning process [30] and promoting autonomous learning [31] In addition, mobile devices offer particular benefits like portability, social interactivity, context sensitivity, connectivity, and individuality [32]. Burston [33] demonstrated that there has been an enormous range of research carried out that is as diverse in its focus as it is varied in the contexts in which it has been used. As alluded to above, however, it has been a problem that much of the research that has taken place with mobile devices has focused either on their use in controlled classroom environments, or has tended to focus on learner attitudes towards learning through mobile devices [34]. High-quality technology has been seen as a barrier in testing and assessment when learning should be considered mobile in the digital era. While the physical characteristics of the mobile device would be thought to play a role, the impacts of the psychological and pedagogical factors are also likely contributing factors [35].

Among the smartphone applications used, social networking apps impact student learning most [11]. With the use of a social networking application on a smartphone, students are able to interact with people anywhere in the world at any time. This enables students to receive unlimited resources, and to have unlimited interactions, for language learning

While a few studies examined the use of smartphones for learning grammar, culture, and vocabulary, the majority of smartphone studies were geared toward the learning of vocabulary, specifically in the classroom setting [36], [37]. For example, Browne and Culligan [36] investigated the use of vocabulary flash cards on students' phones in assisting vocabulary teaching in the classroom. Chen [37] experimented with the use of smartphones by sending learners flash cards through short message service (SMS). These studies reported mostly positive results both in vocabulary learning and outcomes and the learners' perceptions of using a smartphone for language learning.

As smartphones are used for many aspects of language learners' lives, the boundaries between language learning and other tasks become unclear [38]. Viberg and Gronlund [38] advocated that research is necessary when a new communication culture emerges from the advancement of new technology innovations such as smartphones. In particular, it is essential to investigate how smartphones can be employed by teachers or learners. Turning to testing and assessment for the sake of educational professional development, smartphones are called for being used among teachers and learners as an assistance with the application of social networking tools.

Most of the current smartphone studies have a focus on the pedagogical aspects (e.g., teaching of grammar, culture, or vocabulary). However, studies on the use of online application from the Internet networks for language teaching, then testing and assessment procedures are scare.

Hence, the current exploratory study aimed to prove the potentials of Kahoot as an online gaming web-based site in English-as-a-second-language teaching procedures, specifically to test and assess language students' learning and outcomes.

Although educators may have little control over the physical characteristics apart from making sure that activities are suited to the affordances of the devices [39], as Stockwell [40] argues, the teacher may be able to have an impact on psychological factors through adopting an appropriate pedagogy. With that essence, there is a need of mobile application into the pedagogy and instructional period for the sake of teaching and learning efficiency. When teachers are clear and straightforward with their aims at testing and assessment the learning outcomes, students accordingly will be well-oriented to the goals of their studies. 


\section{The Need for Social Networking Training}

Using mobile devices as teaching and learning tools is still new to most schools in Vietnam, a developing country. Thus, many school teachers would consider such devices to be new or unfamiliar educational technology. Much interested in technology application are the teachers, seven teachers $(35 \%)$ felt panicked when told to use the devices in their classroom teaching. Twenty teachers $(100 \%)$ claimed that their initial beliefs and attitudes might influence the effective adoption of the devices in classrooms, but were likely to change once the devices had been adopted. This led to a necessity to apply Kahoot into use with a training session for the sake of self-confidence among teachers.

There is increasing evidence to suggest that training can be an important factor in learning through technology [39] Taking advantage of regular accessibility to mobile devices, teachers and learners tend to spend more time on phones, either to entertain themselves or to work properly. Hence, if teachers and learners have an interest in social networking application for educational purposes, it is necessary for them to get training sessions to maximize the functions of the application. This assures the efficiency in theoretical awareness of technology in testing and assessment then practical goals of the usage in technological tools. The largest factor is that technology itself will often need to be explained and demonstrated to understand the range of functions available, and teachers may also have to help learners deal with issues such as logging in difficulties, connection problems, hardware problems, and so forth. The need for this type of technical training was pointed out [41], who also advocated that training commonly only occurs at the beginning of a course, and that carrying out an ongoing basis had the potential to enhance learner engagement with a technology.

\section{Methodology and Data Collection}

\section{A. Participants}

The participants of the study were twenty teachers and twenty students of the English Department, at the University of Foreign Language Studies, University of Da Nang, Vietnam. They were all thoughtful about their work, and they were willing to share their insights through the research.

There were three male (15\%) and seventeen female $(85 \%)$ teachers recruited for this study. Additionally, they represented a range of years of teaching experience and implementation. There were twelve $(60 \%)$ young teachers with less than five years of teaching experiences (T1) and eight $(40 \%)$ were teachers with more than five years of teaching (T2). This gap created a difference in teachers' opinions, attitudes and reality of practice towards Kahoot as a new introduction to their testing and assessment materials. The only teacher knowing Kahoot but not ever using it in his teaching path was a first-year teacher, who was still working as a teaching assistant at English Department of the University.

This group of teachers was generally comfortable using technology, with all $(100 \%)$ indicating high interests in technology.
Twenty students (50\% males and 50\% females) were randomly chosen among the freshmen, sophomores, juniors and seniors. They all had never got introduced to Kahoot either in their learning processes or in their self-study and practice. This random choice brought a diversity in opinions, attitudes and speed of applying technology on smartphones or mobile devices among learners.

Both twenty teachers and twenty students who took part in the study owned a smartphone or a touch-screen mobile device with Internet accessibility and use Kahoot. The participants also have been accustomed to social networking and using the Internet with the assistance of Wi-fi or Internet connection. The school environment supported technology in teaching and learning. They were equipped with projector screens in the classrooms and wireless services providing Internet connection on mobile devices.

After a brief pre-survey questionnaire into Kahoot usage, all twenty teachers and twenty students agreed to try Kahoot in their teaching and learning as an alternative to testing and assessing the learning outcomes. Face-to-face interviews among teachers and learners were carried out to determine the attitudes towards Kahoot's application. The case study took three weeks of piloting for the practical application and academic efficiency in assessing process.

\section{B. Research Questions}

With the vitality of digital technology and mobile applications in teaching and learning, language testing and assessment system is also in need of technological updates. Hence, Kahoot was introduced to language teaching and learning as a support in testing and revising learners' outcomes after classes. The aim of this study was to examine the possibility of Kahoot application and suggest feasible implications for teachers, learners, and the school teaching curriculum. Specifically, the following questions were addressed:

1) What is Kahoot?

2) How possible is Kahoot applied in language testing and assessment in Vietnamese teaching settings?

3) How do teachers and students feel towards Kahoot application?

4) What are implications for teachers, learners and school teaching curriculum with Kahoot?

\section{Data Collection}

Both quantitative and qualitative data gathering techniques were used with an aim to enhance the research findings. The quantitative data were gathered via questionnaires, which were created to let the participants do online. Questionnaires were designed to ask for the participants' understanding to Kahoot, opinions to technological integration into testing and assessment, attitudes towards Kahoot application as a supplement to the existing testing and assessment materials, then requests for acceptance to necessary training on the mobile devices.

According to the hierarchy of distinct purposes of the research, teachers and students were required to do the questionnaires periodically, which means they first did a pre-survey questionnaire, then another survey after an acceptance to Kahoot during the piloting period. The last one was given to the participants after three weeks of trying 
Kahoot.

The interview questions were also made to further investigate into attitudes of teachers and students towards the use of Kahoot in their education. The participants were interviewed twice. First, questions were to ask teachers and students for their opinions about technology in testing and assessment and their knowing to Kahoot. Then, the interview was conducted after the participants had used Kahoot on mobile devices in three weeks. All the interviews were audio-recorded and transcribed. Qualitative data gathered from individual interviews were analyzed interpretively. The case study of three weeks was chosen for modeling and applying into training teachers and learners to use online web-based application functioning as games to assist teachers in testing and assessing the learners' outcomes via mobile devices such as smartphones.

\section{PROCEDURES}

A survey of examining participants for general understanding was first conducted. It covered the overview of both teachers and students' opinions and attitudes towards mobile learning, technology-application into learning, teaching, testing and assessment; popularity and frequency in using social networks to test and assess learning outcomes, usage of Kahoot in testing and assessment, then a need of training on mobile devices to make use of Kahoot in testing and learning assessment.

The first questionnaire was launched to examine the participants' understanding about Kahoot as an interactive game in language education. The questions focused on the fact whether Vietnamese teachers and learners had ever been exposed to Kahoot which could support their teaching and learning. Interestingly, all teachers and learners showed their surprise in this application at their first sight. After that, with their comfort in interaction and technological education, all the participants agreed to try Kahoot in their educating procedures.

When Kahoot was fully introduced to both teachers and learners as a supporting tool in testing and revising via pre-survey questionnaires, a pilot study of three weeks was delivered to teachers and students with the instructions of the researcher.

Teachers and students were introduced to create a Kahoot account with the assistance of Wi-fi or Internet connection on their smartphones. Students were then required to review what they had learned at class in order to participate in the game created with Kahoot by their teachers. In the meantime, teachers were instructed to put the relevant questions drawn from their lessons to Kahoot in the variety of forms provided on Kahoot platforms. Three hours of the first days were spent on this activity as a whole group of twenty teachers with the researcher. After that, teachers accordingly carried out similar procedures in designing quizzes, questions or short tests for their students regarding their previous lessons. A three-hour meeting was held for twenty teachers to generalize the use and instruct teachers to apply Kahoot. After that, teachers were able to create their own Kahoot platform with related questions to test and revise learners' outcomes. Two teachers $(10 \%)$ in the group of over five-year experience teachers, admitted using the sample created on Kahoot website due to their lack of time in designing a new Kahoot. Eighteen teachers $(90 \%)$ reported that it took them about three to four hours on average to create questions and choose appropriate platforms for their Kahoot games. During three weeks of the pilot study, all twelve T1 teachers were able to integrate at least two Kahoot per week, while the rest eight T2 teachers could make it once a week. This then further reflected the faster pace of technology application into teaching of young $\mathrm{T} 1$ teachers through face-to-face interviews.

The students were requested to review and revise their lesson carefully to take part in the games with Kahoot since teachers were able to either add bonus credits or take away their credits for the participation. This cooperation from teachers and students was highly supportive while this study was carried out.

\section{FINDINGS}

\section{A. What Is Kahoot? Formats, Functions and Feedback of} Kahoot

The question and answer summary to each test on Kahoot designed by teachers to their classes were classified in colors in the form of a statistical chart which helped the assessors match the answers to their students easily. Picture 1 summarized the questions used in the game with the scores players achieved in the allotted time. The players were also ranked according to the scores they had. Correct versus incorrect answers were highlighted in different colors so that teachers could recognize the results conveniently.

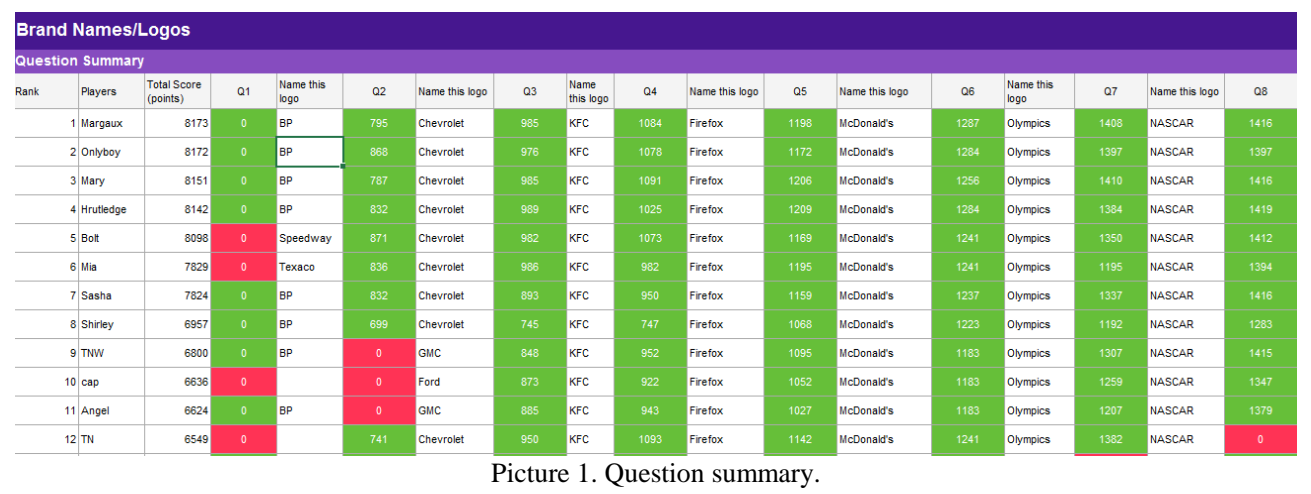

As for its feedback function, Picture 2 showed the general results with the correct answer to the given question in the 
limitation of time given for each answer. It also provided the percentage of correct answers to the questions. This excel-formatted file confirmed the accuracy of the students' answers; showed the numbers of answers received and the average time taken to answer. Nineteen out of twenty teachers $(95 \%)$ agreed that the automatics of this statistics saved teachers' time in class in checking the answers and assuring the clarification among the students' speed in answering the questions. $80 \%$ teachers and $100 \%$ students believed in the accuracy in counting the correct answers of this machinery application in their study. When asked about the preparation procedures to design assessing tests with Kahoot, all twenty teachers reported that it took far more of their time to conduct the first test due to its categories of colors, questions and answers, limited time, or numbers of participants.

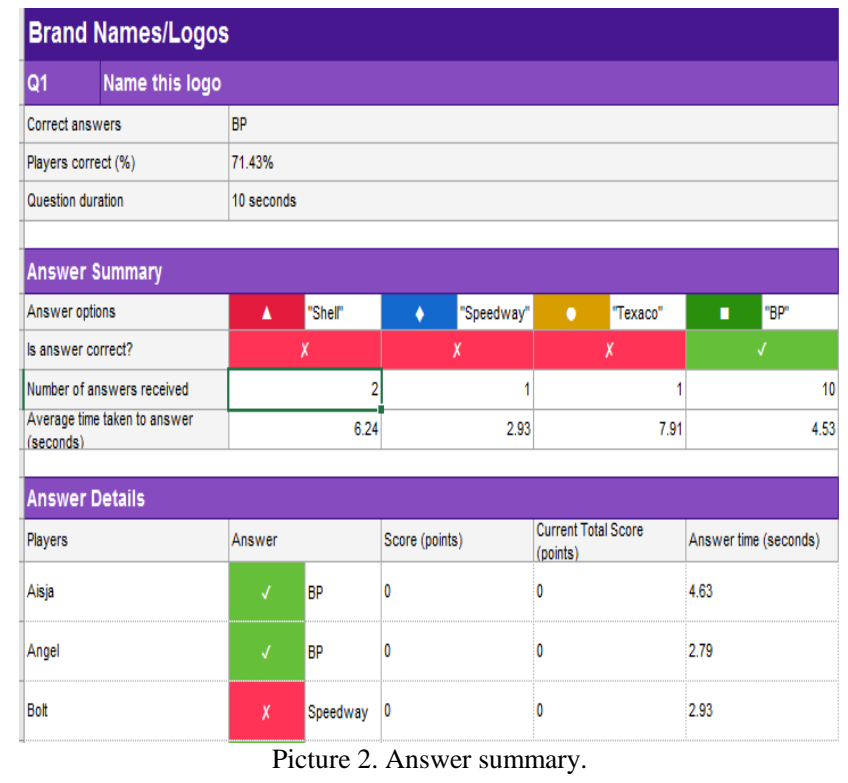

This may cause a conflict among the teachers regarding time-saving effect. In terms of preparation and designing questions, all twenty teachers agreed that it took time to do the tasks, while Kahoot probably saves much of the class time in testing and assessment learners' outcomes. One teacher reported that it took time because that was their first time to use Kahoot, but it saved much of their time later on once the teachers got used to Kahoot. The templates were kept in used but the contents of the questions and answers were changed accordingly. This led to a complete agreement on using Kahoot as a game to revise the students' knowledge during or after the lessons.

As for the teachers, apart from the older ones who still find it troublesome to play with the keyboard or computer apps, the youngster takes Kahoot conveniently in their reviewing and revising the lesson for their students. Eighteen teachers (90\%) agreed that Kahoot saved their lesson planning time, differentiated their teaching resources, assessing steps particularly, and enhanced the speed in memorizing knowledge for their learners.

\section{B. Possibility of Kahoot Usage in Testing and Assessment for Teachers}

After the first week of using Kahoot to test and assess learners' outcomes, twenty teachers were interviewed for the possibility in continuity to use Kahoot. Table II was a summary of ideas and opinions of twenty teachers regarding one week of Kahoot usage. Table II gave a detailed description of Kahoot with its potentials if it is used in Vietnamese classrooms. Table two generalized and listed the teacher participants' answers in ten items.

As can be seen, $100 \%$ teachers wanted to take Kahoot into their classrooms at the beginning, during or at the end of their classes. Only one teacher (5\%) had a fairly understandable worry of Kahoot as a challenge in her classrooms when she wanted her students to take responsibility for their self-disciplined study besides class time. It was shared by the other teachers that they should let the students go for independently critical thinking and decision making, which they chose Kahoot to set it as homework assignment for the students to practice.

TABLE I: FREQUENCY OF TESTING AND ASSESSING AFTER TEACHING FROM TEACHERS

\begin{tabular}{|l|l|}
\hline $\begin{array}{l}\text { Frequency of testing and assessing students' } \\
\text { understanding }\end{array}$ & $\begin{array}{l}\text { Teachers' } \\
\text { answer }\end{array}$ \\
\hline Every class & $60 \%$ \\
\hline Every $2-3$ classes & $35 \%$ \\
\hline Every week & $5 \%$ \\
\hline Every two weeks & $0 \%$ \\
\hline Every month & 0 \\
\hline Never & 0 \\
\hline
\end{tabular}

TABLE II: POSSIBILITY OF USING KAHOOT

\begin{tabular}{|c|c|c|}
\hline Possibility of using Kahoot & $\begin{array}{l}\text { Yes } \\
(\%)\end{array}$ & $\begin{array}{l}\text { No } \\
(\%)\end{array}$ \\
\hline $\begin{array}{l}\text { 1. Start off the lesson as brainstorming, or } \\
\text { checking-up. }\end{array}$ & 90 & 0 \\
\hline $\begin{array}{l}\text { 2. Preview the content, include instructional } \\
\text { imagery or videos }\end{array}$ & 100 & 0 \\
\hline 3. Test individual knowledge & 100 & 0 \\
\hline $\begin{array}{l}\text { 4. Test and assess learners' understanding after } \\
\text { the lessons }\end{array}$ & 100 & 0 \\
\hline $\begin{array}{l}\text { 5. Brainstorm, practice or consolidate } \\
\text { knowledge of the day }\end{array}$ & 100 & 0 \\
\hline $\begin{array}{l}\text { 6. Review, revise and reinforce: revise and recap } \\
\text { topics, reinforce knowledge }\end{array}$ & 100 & 0 \\
\hline 7. Pre-assess and practice before exams & 100 & 0 \\
\hline $\begin{array}{l}\text { 8. Re-energise and reward: break the ice, reward } \\
\text { good behaviours }\end{array}$ & 100 & 0 \\
\hline $\begin{array}{l}\text { 9. Challenge students to create their own Kahoot } \\
\text { for self-study or self-entertainment, get } \\
\text { students distracted from studying }\end{array}$ & 95 & 5 \\
\hline $\begin{array}{l}\text { 10. Will you use Kahoot in your teaching and } \\
\text { learning? }\end{array}$ & 100 & 0 \\
\hline
\end{tabular}

Shortly, $100 \%$ of the teachers decided to use Kahoot for their classes in designing relevant tests or quizzes as consolidation.

\section{Application of Kahoot into Vietnamese Teaching Settings}

After the first day of Kahoot introduction and three weeks of adding Kahoot as an assistance to teachers' testing and assessment tools, twenty teachers shared their descriptions, 
opinions and attitudes towards the possibility of Kahoot in their classrooms. All twenty teachers $(100 \%)$ claimed that Kahoot benefitted them more than the possible downsides of the technological problems and networking inconvenience might cause. Teachers stated that a detailed summary of final scores, raw question lists, the students' correct or incorrect answers with their timing and ranking the students' achievement in Kahoot results provided clear reports for their assessing process in terms of the students' understanding, memorizing and speeding in their learning. Additionally, teachers are allowed to set the time allotted on Kahoot platform to each answer so that they can assume if the students are able to give the answers or not. As a result, all teachers came to an agreement that this function of Kahoot saved time in testing and assessing learners and gathering the data of the students' performances after class. When teachers were asked to point out the most useful significance of Kahoot, twelve out of twenty teachers $(60 \%)$ said that they preferred the ranking option of the result summary. The teachers further clarified that answer ranking automatically in the Excel format platform was considered reliable and fair in grading students when necessary. In this part of function, the final results from Kahoot are hierarchically put in order from the highest scores to the lower ones, which is calculated and ranked according to the format of excel presentation. This means teachers did not need to record the scores and put them into order for the final announcement. Instead, Kahoot provides the results in a precisely automatic way, which proved the clarity and fairness in scoring for the student players. The remaining eight teachers $(40 \%)$ believed that Kahoot brought about creativeness in designing short tests for their learners with the engagement of images, videos and speedy race of scoring. With this function, teachers got all of their learners' involvement into competing individually or in teams, which forced the learners to draw attention in remembering and recalling what they had been learning during the class. Similarly, when it came to students' surveys, ten out of twenty students loved to use Kahoot for their competitive awards at the end of the game, the rewarding could be either extra bonus credits, good marks or little sweets. All these things were considered motivation in teaching and learning for both teachers and students. "Kahoot is simple to use as a testing and assessing material; easy to design and saves the teachers' lesson planning time", stated by a teacher. Plus, Kahoot was designed as an interactive game for learners to participate in at class; therefore, regarding motivating factors, Kahoot created motivation in learning for students, which betters the learning outcomes. From the student's perspective, the student believed that his scores and speed of reviewing the lesson improved better once he played Kahoot and self-practiced at home with his teachers' assignment on Kahoot. What he had been taught at class was reviewed and revised in the form of games that the teacher designed. As a result, he was not forced to do much homework but do the straightforward focus of reviewing and revision.

\section{Teachers' and Learners' Understandings and Attitudes towards Kahoot}

It is still a question open to discussion as to whether social networking could be used as another existing material to engage students and support learning for both students and staff and should be more included in school for educational goals. Before being introduced to Kahoot, all twenty teachers and twenty students did not have an idea of Kahoot in testing and assessment of their learning outcomes. The only teacher had heard of Kahoot while he was playing a competitive short quiz game with his classmates. He had never used Kahoot to design related questions for reviewing or revising learners' knowledge. Hence, a questionnaire about the frequency of Internet accessibility, along with the usage of online application, saying Kahoot, in testing and assessment among teachers and learners was surveyed.

\section{E. From the Questionnaires}

- Teachers' general understanding about Kahoot and the usage

Twelve out of twenty (60\%) teachers always designed different types of tests after every class to test and assess their learners' outcomes. They support the use of testing and assessment right after class that students can remember far more knowledge than they save the knowledge at home. Meanwhile $35 \%$ of the teachers (seven people) tested and assessed their students every two or three classes for general revisions. Only one teacher said she tested the students once a week, after every unit from textbooks. There were no teachers who never test or assess their learners' outcomes or even none of the teachers got the students tested or assessed every month. The follow-up interview questions gave more detailed description of the reasons for regularly testing and assessment the learning process. Twenty teachers believed that tests after lessons proved the students' understanding and memorizing what the students had been taught at class. Eight teachers $(40 \%)$ shared a common idea on the reliability of their teaching via forms of tests. All twenty teachers used written tests (Figure 1\&2), including multiple choices, short-answered questions, gap filling or open discussed questions, as formative assessment. There were none of the twenty teachers ever using online application such as Kahoot to design questions for reviewing or revising the lessons before. The detailed frequency of testing and assessing after teaching from teachers surveyed is described in Table I.

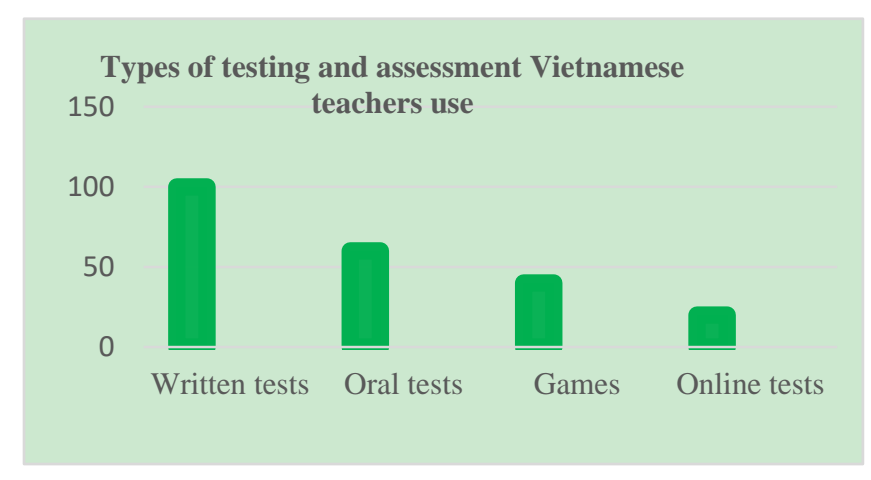

Fig. 1. Teacher participants current use of tech tools in testing and assessment.

Although all twenty teachers reported that technology had been used in testing and assessment learning outcomes, no teachers had ever applied online web-based game such as Kahoot into their testing and assessment. All twenty teachers 
and twenty students confirmed that they always had tests after classes for reviewing and revision. The types of tests could be oral, written or game-based testing formats assigned by their teachers, but none of the tests had been online designed in the form of game as Kahoot.

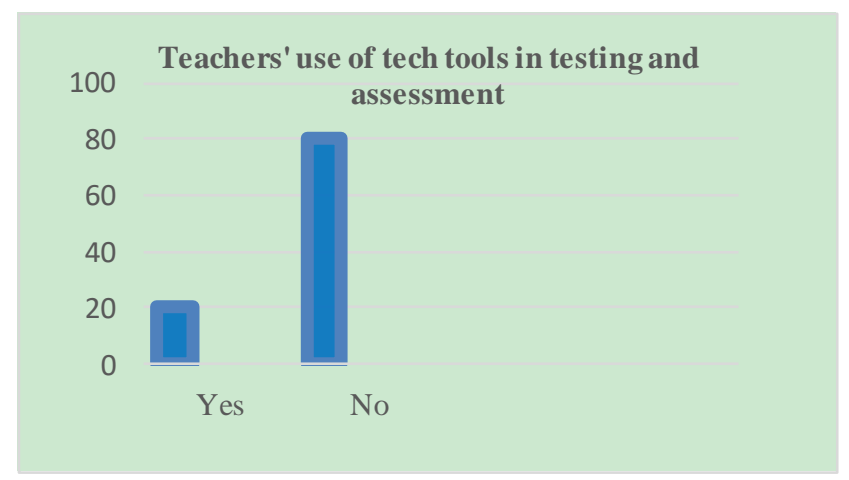

Fig. 2. Types of testing and assessment Vietnamese teachers currently use.

In addition, the figures show that teachers are highly aware of the importance to review, revise and reinforce the knowledge for their learners after class. The final goals are to ensure what learners are able to achieve after being taught at class, then apply the learned knowledge into practical lives. The survey showed that technological application, Kahoot as an example, was supported to introduce to teachers, especially applying to use with mobile devices such as smartphones. One teacher reported that "games, in any form increases motivation in the classroom through engagement. When teachers understand the root of motivation in learning for students, teachers will be able to make use of any means of teaching tools or materials in testing and assessment learners' outcomes." All things considered, teaching English as a foreign language is, without a doubt, to certify learners' language acquisition, which is supposed to display through their outcomes of communication and proper usage in different contexts.

- Students' general understanding about Kahoot and the usage

From the initial general survey on twenty students about Kahoot, twenty students (100\%) reported not to have been exposed to Kahoot as an online game in learning ever before. However, this acted as a surprise to all student participants with high curiosity of Kahoot on their touch-screen mobile devices. Plus, when playing Kahoot, learners were mainly divided into teams or groups, which gained collaboration in learning among the students. Twelve students $(60 \%)$ were aware of the absolute importance of technology in current learning strategies. They believed that technologies could deter them from boredom of traditional written tests. They would instead enhance promotion in more regular review and revision after classes in order to join Kahoot designed by their teachers. Six other students $(30 \%)$ learners claimed the neutral vitality of technological tools in their education. The last two students $(10 \%)$ in the study showed no importance of tech tools due to the distraction of higher technology in their education. These students were interested in Kahoot with a tempt to try it at their classes, even they did not support the positives of technology into their learning. The results from the questionnaires displayed a diversity in attention of twenty students into technology in education, in general, and Kahoot as an online application, in particular. Nevertheless, the majority of student participants $(90 \%)$ revealed a crucial role of technology in education with regards to testing and revising lessons handy.

\section{1) From the interviews}

The interviews revealed several confirmations on the vitality of technological tools in teaching and learning English as a foreign language of Vietnamese teachers and students.

From students' perspectives, all twenty of them expressed their excitement about Kahoot when they were able to use their phones in classrooms officially. It is the fact that phones are not allowed to use at class in order not to get the students distracted from learning. However, with an assurance of learning only, students raise their awareness of independent learning styles for their efficiency. Eighteen students (90\%) satisfied with the use of Kahoot on smartphones for the first time with a reason of high tech competencies. Two other students (10\%) were able to join Kahoot at their first try, but with a hesitation of internet connection linking to viruses or possible online deterrents on their phones. However, all twenty students (20\%) showed a full agreement on using Kahoot for a revision of their lessons, which changed their mind of written or paper tests.

From teachers' perspectives, a similar bias was revealed. All twelve teachers $(60 \%)$ with less than five year teaching experience showed a smooth usage of Kahoot with their mobile devices such as laptops or iPads. The only teacher (5\%) with twenty-three years of teaching expressed her disappointment at time-consuming design of quizzes with Kahoot app. However, she was then carefully instructed to use online Kahoot sample at the first try. She then found out her involvement and started to use Kahoot more properly.

\section{2) Teachers' and learners' attitudes towards Kahoot}

After three weeks of teaching and learning with Kahoot application, all twenty teachers and twenty students were interviewed for interests to continue using Kahoot as a postlearning games with consolidating purposes. Teachers and students agreed on the positive effects of Kahoot in testing and assessing the learning outcomes, which creates diverse options to test and assess learning. Kahoot did not take a lot of time as a game to play with during class time so that teachers could flexibly apply it before, during or after the lessons started. Due to the given amount of the 45-minute class time, consolidation was supposed to take eight to twelve minutes at every class, reported seventeen teachers $(85 \%)$. Therefore, a three-minute game of Kahoot with an allotted time of fifteen or twenty seconds for each answer was chosen by all of the teachers $(100 \%)$ when they designed the tasks. Besides, it did not take the students too much time or leak private information to create an account on Kahoot online. This convenience made students confident in providing their necessary information such as names, user names, email addresses to sign up an account online.

Turning to the students' attitudes towards Kahoot, they were keen to join in groups and play the games with their teammates. All twenty students $(100 \%)$ were highly excited about the continuation in using Kahoot to do revision. The 
students were aware of the accurate answers and the speed of ranking among their answers; therefore, they were motivated to tried hard ahead of the revision class. In the first week of the study, in terms of liking Kahoot, sixteen students $(80 \%)$ completely did like it, two students (10\%) liked it in a neutral sense, and the rest two students $(10 \%)$ quite liked Kahoot. The reasons for this tendency of liking were due to the formats of Kahoot and the contents designed by each teacher. The sixteen students felt satisfied with all what the teachers combined in the question sets, while the other four students only witnessed the difference in the contents instead of the format as well. This caused them to be feeling bored when the teachers repeated the forms of quizzes. This opinion was transferred to the teachers' group in the second week of the pilot study and they started to differentiate the questions' types such as multiple choice, gap-fill, yes-no questions, or open questions. The students were again asked for their liking as for the consistency of the case study. This time experienced a full agreement among the students when they all show high satisfaction $(90 \%)$ with Kahoot for their revisions. After the whole three weeks of the pilot study, all twenty students $(100 \%)$ met their agreement in using Kahoot to do the revision with positive feedback, including class time saving, effectiveness in memorizing knowledge, collaborative improvement, competitiveness for hard work, and relaxing comfort. The students concluded that Kahoot can be used in any class if the teachers are introduced to this application broadly.

Having a deeper look at the feasibility of Kahoot into teaching, eighteen out of twenty teachers (90\%) found Kahoot easy to use and practice, while there were two others disagreed on its simplicity due to its digital language and online requirements. One teacher with twenty-three years of teaching (5\%) said, "without any doubt, younger teachers are faster in acquiring technology and developing their creativity in comparison to the long-term teaching experiences of the prior generations." She mentioned this as she thought the aging hindered her from using much of technology in testing and assessment rather than formative assessment such as written or oral tests. This is considered a current drawback in applying technology into teaching in Viet Nam. However, this is a training issue only. Therefore, different training or another study should be taken to look further on the reality of Vietnamese teaching settings for a widespread of technological immersion into teaching over the digital periods.

\section{IMPLICATIONS}

Hence, this paper resulted some implications for teachers, students and the school's teaching curriculum for the introduction of Kahoot into testing and assessment in Vietnamese educational settings.

\section{A. Implications for Teachers}

In the era of the $21^{\text {st }}$ century of digital application, teachers' crucial roles are mentoring, stimulating, provoking and engaging the students into learning, not just delivering all what is displayed in the books. Web-based tech tools such as Kahoot was introduced as an assessment alternative for teachers to test the students' learning outcomes. Therefore, teachers are encouraged to engage Kahoot in testing and assessment system, together with the traditional types of tests and assessment being used such as written or oral forms. Teachers need to be aware of the flexibility of technology integration along with its drawbacks of technological adjustments or continuous updates in order not to passively rely on tech tools.

\section{B. Implications for Students}

Kahoot is designed as a competitive game that draws the students', young learners' attention by its speed and touchable adaptability. Besides, Kahoot can be designed as homework for learners to study on their own. Therefore, students are expected to take advantage of Kahoot platform and its surfaces to gain high interests in doing reviewing and revision lessons after learning. Students can choose to learn individually or work in groups of many students. Consequently, Kahoot can play a fundamental role in establishing solidarity among learners and reinforce learners' creativity in learning.

\section{Implications for Schools' Teaching Curriculum}

Teachers and students are the key participants of every English lesson, they are implied to integrate technology, Kahoot as recommendation, in testing and assessment the learning outcomes. This study desired to give some implications for the school teaching curriculum in adding social networks into testing and assessment system. The administration, first, is required to build a strong network of controlling the use of technology among young learners. There have been a variety of good and bad online sources that students may get access to. Therefore, positive or negative effects may be brought about to the learners if they are not directed to use in the right ways. More importantly, training courses of social networking with clear instructions and practical recommendation on mobile devices such as smartphones, tablets or laptops should be added to the professional development strategies.

\section{DISCUSSION}

Teachers take a huge advantage of timing, lesson planning and classroom management, while students boost their learning motivation and engagement into reviewing, revising and reinforcing their learned knowledge via games with Kahoot. For further discussion, another follow-up part of revision was required after the teachers let the students play Kahoot for the sake of academic enhancement at schools. That could be a short presentation of a group or a small talk among groups of students for further discussions concluding from the details gathered in Kahoot. Reviewing and revision to test and assess what students had been taught at class were not enough for students regarding the purposes of integration, communication and self-study. Therefore, further talks using the information from Kahoot should be used as add-ons to the students' drills. Besides, it is obviously seen that technical problems related to Internet connection due to various generations of smartphones of the are considered a hindrance. This may lead to differentiating the students' speed in 
answering. In terms of competitiveness, students can get distracted or demotivated if teachers are not aware of this matter.

In addition, different levels of ages have had dramatic effects on teachers' technology acquisition; therefore, further training is highly required for the early teachers and staff with clear details of instructions and longer periods of practices and drills. Young learners need being controlled once they are allowed to get access to digital devices since many of them may lose concentration on studying but for gaming and entertaining.

\section{CONCLUSION}

The purpose of this study was to examine in depth how teachers integrate technology for learning in order to generate a taxonomy of technology use for future research and for enhancing teaching practice. Teachers highlighted how technology provides efficiencies for educators and learners, making daily routines like checking and grading homework quicker and easier, which in turn helped teachers restructure their time to focus more on instructional planning and delivery.

It is concluded that both teachers and learners have had positives views and attitudes to social networking in their education progress. Both parties agreed that the benefits of Kahoot outweighed those of its drawbacks for betterment in their testing and assessment processes. Due to the increasing presence of English as an international language for non-English speaking countries to take it as a core subject in their classrooms, there have been reasonable accountability to examine the assessment measures educators have been using. Testing and assessment is not an isolated activity but a component of progressing teaching and learning processes. Teachers must understand the power of assessment data in helping them provide the evidence that students are learning and making progress. There is a need to consider the content of teaching implications of using social networks and the relationships between the teacher and the students, as well as consider how learners use social networks in their earning to make it a better "fit" to their everyday lives. Students' engagement into learning will increase the quality of teaching and learning procedures by enhancing their learning outcomes. When teachers have the appropriate attraction to test and assess the learners, students are better motivated in learning. Vietnamese teachers and students expect to call for further research to look for more precise keys to teaching, learning and assessing success in the digital era nowadays. In addition to that, negative impacts causing by a variety of sources from the online browsers are supposed to researched and limited once it is assumed to be applied into a wider range of testing and assessment system.

\section{ACKNOWLEDGMENT}

The authors highly appreciated the enthusiastic and energetic participation of members from Danang University of Foreign Language Studies in the conduction of this research.

\section{REFERENCES}

[1] APA Work Group of the Board of Educational Affairs, Learner-Centreed Psychology Principles: A Framework for School Reform and Redesign, Washington, DC.: American Psychological Association, 1997.

[2] C. Darnon et al., "Achievement goals in social interactions: Learning with mastery vs. performance goals," Motivation and Emotion, vol. 31, no. 1, pp. 61-70, 2007.

[3] T. Schellens and M. Valcke, "Collaborative learning in asynchronous discussion groups: What about the impact on cognitive processing?" Computers in Human Behaviour, vol. 21, no. 6, pp. 957-975, 2005.

[4] T. T. Gao et al., "Consumers un-tethered: A three-market empirical study of consumers' mobile marketing acceptance," Journal of Business Research, vol. 66, no. 12, pp. 2536-2544, 2013.

[5] C. Evans, "The effectiveness of m-learning in the form of podcast revision lectures in higher education," Computers \& Education, vol. 50, no. 2, pp. 491-498, 2008

[6] J. Twyman, "Leveraging technology to accelerate school turnaround," The State Role in School Turnaround: Emerging Best Practices, pp. 99-113, 2014, San Francisco, CA: WEstEd.

[7] R. Godwin-Jones, "The evolving roles of language teachers: Trained coders, local researchers, global citizens," Language Learning \& Technology, vol. 19, no. 1, pp. 10-22, 2015

[8] K. Barrs, "Mobility in learning: The feasibility of encouraging language learning on smartphones," Studies in Self-access Learning Journal, vol. 2, no. 3, pp. 228-233, 2011.

[9] M. Osborne, "An autoethnographic study of the use of mobile devices to support foreign language vocabulary learning," SiSAL Journal, vol. 4, no. 4, pp. 295-307, 2013.

[10] H. Poll, Pearson Student Mobile Device Survey 2014: National Report: College Students, 2014.

[11] C. Currie, "Impact of mobile computing: Anticipating the effects on the campus," Planning for Higher Education, vol. 41, no. 2, pp. 169-178, 2013.

[12] Tapshield. (2015). Data sheet-college demographic smartphone ownership \& usage. [Online]. Available: http://tapshield.com/data-sheet-college-demographic-smartphone-own ership-usage/

[13] J. Gikas and M. M. Grant, "Mobile computing devices in higher education: Student perspectives on learning with cell phones, smartphones \& social media," Internet and Higher Education, vol. 19, pp. 18-26, 2013.

[14] C. Greenhow, "Youth, learning and social media," Journal of Educational Computing Research, vol. 45, no. 2, pp. 139-146, 2011.

[15] K. Burke, Balance Assessment: from Formative to Summative, Georgia: Solution Tree Press, pp. 19-25, 2009.

[16] A. I. Fageeh, "EFL student and faculty perceptions of and attitudes towards online testing in the medium of Blackboar: Promises and challenges," The JALT CALL Journal, vol. 11, no. 1, pp. 41-62, 2015.

[17] R. Stannard and A. Basiel, "A practice-based exploration of technology enhanced assessment for English language teaching," Innovations in Learning Technologies for English Language Teaching, pp.145-74, London: British Council, 2013

[18] J. B. Biggs and C. Tang, Teaching for Quality Learning at University ( $3^{\text {rd }}$ ed.). Maidenhead: McGraw Hill Education \& Open University Press, 2007.

[19] US Department of Education, Office of Educational Technology, Enhancing Teaching and Learning through Education Data Mining and Learning Analytics: An Issue Brief, Washington, DC: Author, 2012.

[20] K. Gray et al., Web 2.0 Authoring Tools in Higher Education Learning and Teaching: New Directions for Assessment and Academic Integrity: A Framework for Field-testing and Refining Good Practice Guidelines in Pilot Projects at Australian Universities During Semester One 2010 , 2010.

[21] University of New South Wales. (2015). UNSW Assessment as Learning Toolkit. [Online]. Available: https://teaching.unsw.edu.au/assessment-toolkit

[22] L. Johnson et al., NMC Horizon Report: Higher Education Edition, Austin, Texas: The New Media Consortium, 2015.

[23] K. Kaufman, " 21 ways to $21^{\text {st }}$ century skills: Why students need them and ideas for practical implementation," Kappa Delta Pi Record, vol. 49 , no. 2 , pp. $78-83,2013$

[24] M. Fullan and M. Langworthy, A Rich Seam: How New Pedagogies Find Deep Learning, Harlow: Pearson, 2014.

[25] D. Byrne, Games. Teaching Oral English, Harlow: Longman Group UK Limited, pp. 101-103, 1995. 
[26] J. Hadfield, "A collection of games and activities for low to mid-intermediate students of English," Intermediate Communication Games, Hong Kong: Thomus and Nelson and Nelson \& Sons Ltd, 1990.

[27] A. Ersoz, "Six games for the EFL/ESL classroom," The Interet TESL Journal, vol. 6, no. 6, pp. 43-58, 2000.

[28] M. E. Avedon and B. S. Brian, "Learning through games," The Study of Games, New York: John Wiley \& Sons, Inc, pp. 315-321, 1971.

[29] P. A. R. Amato, Making It Happen, New York: Addison-Wesley Publishing Group, pp. 192-199, 1996.

[30] E. Smeets, "Does ICT contribute to powerful learning environments in primary education?" Computer \& Education, vol. 44, pp. 345-345, 2004.

[31] M. J. Luzon and M. I. Gonzalez, "Using the internet to promote autonomous learning in ESP," Information Technologies in Language for Specific Purposes. Issues and Prospects, New York: Springer, 177-190, 2006

[32] E. Klopfer et al., "Environment detectives: PDAs as a windown into a virtual simulated world," in Proc. from IEEE International Workshop on Wireless and Mobile Technologies in Education, 2002.

[33] J. Burston, "Mobile-assisted language learning: A selected annotated-bibliography of implementation studies 1994-2012," Language Learning \& Technology, vol. 17, no. 3, pp. 157-224, 2013.

[34] G. Stockwell, "Mobile language learning," Routledge Handbook of Language Learning \& Technology, Abingdon: Routledge, 2016, pp. 296-309.

[35] S. Wang and M. Higgins, "Limitations of mobile phone learning," The JALT CALL Journal, vol. 2, no. 1, pp. 3-14.

[36] C. Browne and B. Culligan, "Combining technology and irt testing to build student knowledge of high frequency vocabulary," The JALT CALL Journal, vol. 4, no. 2, pp. 3-16, 2008.

[37] N. S. Chen et al., "Effects of short-term memory and content representation type on mobile language learning," Language Learning \& Technology, vol. 12, no. 3, pp. 93-113, 2008.
[38] O. Viberg and A. Gronlund, "Cross-cultural analysis of users' attitudes toward the use of mobile devices in second and foreign language learning in higher education: A case from Sweden and China," Computers \& Education, vol. 69, pp. 169-180, 2013.

[39] P. Hubbard, "Making a case for learner training in technology enhanced language learning environments," CALICO Journal, vol. 30, no. 2, pp. 163-178, 2013.

[40] G. Stockwell, "Investigating learner preparedness for and usage patterns of mobile learning," ReCALL, vol. 20, no. 3, pp. 253-270, 2008.

[41] P. Hubbard, "Learner training for effective use of call," New Perspectives on Call for Second Language Classrooms, Mahwah, nj: Lawrence Erlbaum, 2004.

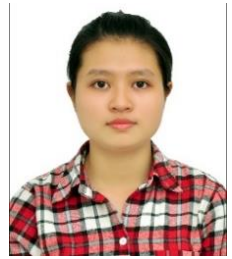

Thuy Thi Thanh Nguyen is a Ph.D. student majoring in technological education and a university lecturer (M.Ed.) of English as a foreign language for special purposes. Her research interests include methodologies in teaching English as a foreign language for special purposes, integrating information and communication technologies (ICT) into teaching and learning languages, testing and assessment learners' outcomes with computer-assisted or mobile devices.

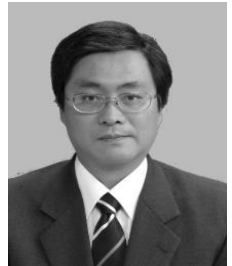

Takashi Yukawa is a professor at Nagaoka University of Technology, majoring in computer supported collaborative learning, and e-learning. His studies focus on integrating information and communication technologies (ICT) into education, testing and assessing learners' outcomes with computer-assisted or mobile devices. His research interests include pedagogical approaches and educational technology with the aim of learners' acquisition and higher improvement in learning. 